\title{
Turbulent mixing and phytoplankton spring bloom development in a deep lake
}

\author{
Frank Peeters, Dietmar Straile, Andreas Lorke, and Dieter Ollinger \\ Limnological Institute, University of Konstanz, D-78464 Konstanz, Germany
}

\begin{abstract}
A one-dimensional (1-D) mechanistic phytoplankton model combined with a 1-D hydrodynamic model was applied to simulate phytoplankton growth during winter and spring in deep monomictic Upper Lake Constance. Modeled chlorophyll $a$ concentrations agree well with data from the 8-y time period considered. In particular, the interannual variation in the timing of phytoplankton growth is adequately simulated by the model. The onset of phytoplankton blooms in Upper Lake Constance is not sensitive to variations in the photosynthetically active radiation, the sinking velocity of the algae, or the effect of water temperature on biological process rates, but is primarily determined by turbulent diffusion (i.e., by the transition from strong mixing in winter and early spring to weak mixing). The transition in mixing conditions and thus also the beginning of phytoplankton population growth correlates with the build up of the first slight temperature stratification. Simulations performed without consideration of phytoplankton loss due to grazing overestimate algal biomass soon after the onset of algal growth. Including grazing by zooplankton substantially improves the agreement between model and data and suggests that ciliate grazing in particular leads to a significant reduction of phytoplankton abundance in spring after the start of the algal bloom.
\end{abstract}

The mixing period in oceans and deep lakes can be considered to be the aquatic analogue of barren land (Reynolds 1997). During the winter mixing period primary productivity is limited by low temperature, the seasonal minimum of solar radiation, the maximum of its reflection at the water surface, and by turbulent mixing that transports phytoplankton below the euphotic zone. Only with increasing solar radiation, temperature, and thermal stratification does the phytoplankton bloom start to develop (Bleiker and Schanz 1997; Gaedke et al. 1998; Tian et al. 2003b) and forms the basis of further seasonal succession (e.g., Sommer et al. 1986), and the development of plankton trophic structure and food webs (Straile 2005). Understanding and predicting the onset and development of the phytoplankton bloom is hence of fundamental importance in predicting the response of aquatic ecosystems to environmental change.

The start of the phytoplankton bloom in temperate regions is associated with the onset of stratification, increased solar radiation, and a warming of surface waters. Especially in deep water bodies, it is the absence of deepwater mixing that strongly determines light availability for phytoplankton (Tian et al. 2003b). Consequently, plankton

\section{Acknowledgments}

We thank H. Rossknecht (Institut für Seenforschung, Langenargen) for the long-term temperature data set, all scientists and technicians involved in the collection and compilation of the biological data set, and Kristine Schalau for the preparation of the thermistor data. The data set at Sta. BM was established within the Special Collaborative Programme (SFB) 248 "Cycling of Matter in Lake Constance," supported by Deutsche Forschungsgemeinschaft (DFG). We also thank two anonymous referees for their constructive comments which helped to improve the manuscript.

This research was conducted within the program AQUASHIFT (SPP 1162) funded by the DFG. Additional support was by the European Union within the framework of the European Commission project 'CLIME' (EVK1-CT-2002-00121).

Konstanzer Online-Publikations-System (KOPS)

URL: http://www.ub.uni-konstanz.de/kops/volltexte/2007/3829/

URN: http://nbn-resolving.de/urn:nbn:de:bsz:352-opus-38295 blooms can develop immediately after the onset of stratification (Bleiker and Schanz 1997; Gaedke et al. 1998; Tian et al. 2003b) or in the absence of stratification when wind-driven vertical mixing is absent or very weak (Townsend et al. 1992; Bleiker and Schanz 1997). In more shallow systems, the increase in light availability due to increasing hours of daylight (Tian et al. 2003a) or the melting of the ice cover (Adrian et al. 1999) results into the plankton bloom.

The aim of this study is to investigate to what extent the onset and early development of the phytoplankton spring bloom depends on seasonal changes in turbulent mixing, solar radiation, water temperature, and grazing. The analysis is based on a mechanistic model that is applied to the conditions in Upper Lake Constance. Two different modeling approaches are commonly employed to increase understanding of aquatic systems. On the one hand, the response of phytoplankton development is investigated on the basis of minimal models (Gragnani et al. 1999; Huisman et al. 2002, Huppert et al. 2002). The aim of such studies is, for example, to identify the range of turbulent diffusivities and sinking rates that allow phytoplankton populations to survive (e.g., Huisman et al. 2002), to characterize the nutrient regimes resulting in phytoplankton blooms (Huppert et al. 2002), or to investigate the competition between phytoplankton species in a dynamic environment where the phytoplankton concentration affects underwater light intensity (e.g., Huisman et al. 2004). These minimal models are not designed for a direct comparison with field data but are intended to provide principal insights into ecological mechanisms. On the other hand, complex ecosystem models are used to simulate plankton, nutrients, and other water constituents under field conditions. The aim of these studies is to provide models that enable a prognosis of the plankton development under changing environmental conditions due to climate change or anthropogenic impacts. The model design is usually validated by a direct comparison of 
simulations with field data (e.g., Hamilton and Schladow 1997; Omlin et al. 2001b). Such ecosystem models commonly consider many components such as different groups of phytoplankton and zooplankton, as well as nutrients or even microbial degradation in sediments, to account for the seasonal changes in the processes limiting primary production and the seasonally varying predation pressure. Because of the large number of state variables required, these models often have a coarse spatial and temporal resolution considering, for example, daily mean conditions for light and mixing. In addition, it is often very difficult to adequately estimate values for the multitude of parameters in such complex ecosystem models (Omlin et al. 2001a).

In this paper we have chosen a modeling approach intermediate between the two extremes mentioned above (see also Tian et al. 2003a). Our investigation is limited to winter and spring conditions and focuses on the onset of phytoplankton growth. Because we simulate phytoplankton growth under actual field conditions, a comparison between model results and field data can be used to validate the model behavior and to investigate limitations in the model design. The restriction to winter and early spring allows for a significant simplification of the model compared with full ecosystem models, because during that time, phytoplankton growth in Upper Lake Constance is limited only by light conditions but not yet by nutrients (Sommer et al. 1986). In addition, food web interactions are not yet as complex as they are later in the season (Sommer et al. 1986). This allows us to use a very simple model to simulate phytoplankton dynamics. In this respect, the model is close to a minimal model approach. However, because the physical conditions considered correspond to actual field conditions the model results can be directly employed to interpret plankton abundance data.

\section{Methods}

Study site-Upper Lake Constance is a large and deep (mean depth, $102 \mathrm{~m}$; maximum depth, $250 \mathrm{~m}$ ) prealpine lake. It consists of a large eastern basin (Main Basin; maximum depth, $254 \mathrm{~m}$ ) and a smaller western basin (Lake Überlingen; maximum depth, $144 \mathrm{~m}$ ), which is separated from the Main Basin by a sill that reaches up to $80 \mathrm{~m}$ below the lake surface. The mixing regime of Upper Lake Constance can be classified as monomictic in most years. Ice cover develops rarely; the last full ice cover occurred in 1963. The trophic status of Upper Lake Constance changed strongly during the last century with a 10 -fold increase in total phosphorus concentrations from the 1950s to the late 1970s, and an almost-as-fast decrease back to the levels of the 1950s during the last $25 \mathrm{yr}$ (Güde et al. 1998). Consequences of cultural eutrophication and reoligotrophication on plankton populations were studied in great detail during the past few decades (see articles in Bäuerle and Gaedke 1998).

Data set-In this study we focus on the time period between 1979 and 1994. The meteorological data set employed is based on hourly data on wind speed, wind

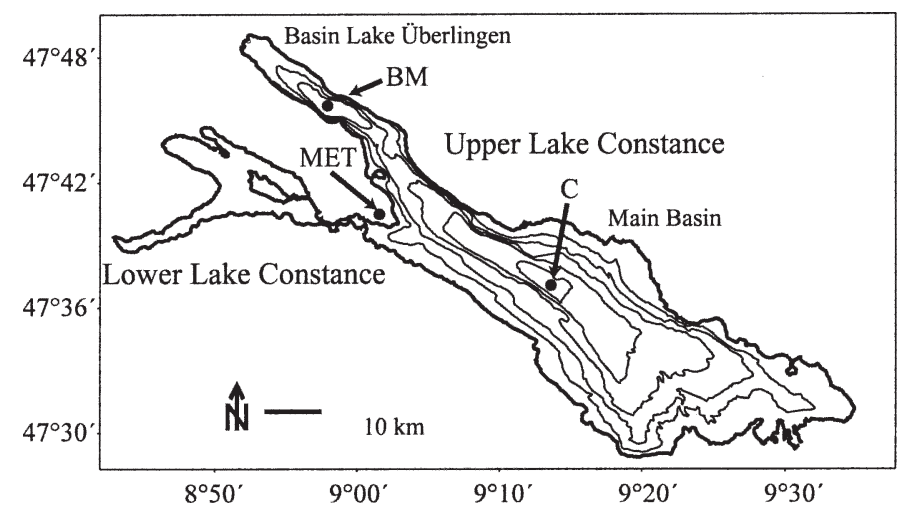

Fig. 1. Map of Lake Constance including the locations of data collection. C: Long-term temperature data. BM: biological data and thermistor data. MET: meteorological station, Konstanz. Contour lines depict isopleths in 50-m-depth intervals.

direction, air temperature, solar radiation, humidity, and cloud cover measured at the DWD (German National Meteorological Service, Deutscher Wetterdienst) station in Konstanz (Fig. 1) at a height of $17 \mathrm{~m}$ above ground. The station is located $47 \mathrm{~m}$ above the surface level of Lake Constance. Wind speed measurements directly on the lake in the basin Lake Überlingen (Sta. BM in Fig. 1) suggest that wind speeds $10 \mathrm{~m}$ above the lake surface are 1.3 times greater than the wind speeds measured at the DWD station in Konstanz (Zenger et al. 1990). Therefore, the data on wind speed from the DWD station were scaled by a factor of 1.3 throughout this study. Note, however, that this is only a crude estimate of the typical wind speed relevant for entire Upper Lake Constance, because wind speed can vary substantially between different locations on the lake (Bäuerle et al. 1998).

Monthly to biweekly temperature profiles are available for the entire time period of interest from 1979 to 1994 (Straile et al. 2003). Temperature was measured at Sta. C (Fig. 1) at depths of $0,5,10,15,20,30,50,100,200$, and $250 \mathrm{~m}$. The accuracy of these data is $0.1^{\circ} \mathrm{C}$. A data set on temperatures with a high temporal resolution covering the time period between 1987 and 1994 was obtained from two thermistor chains consisting of a total of 22 thermistors (Aanderaa, Inc.) installed at Sta. BM (Fig. 1) between a depth of $3.5 \mathrm{~m}$ and $140 \mathrm{~m}$. The vertical spacing of the thermistors was about $3 \mathrm{~m}$ in the top $30 \mathrm{~m}$, and about $10 \mathrm{~m}$ below a depth of $30 \mathrm{~m}$. The thermistors had a temperature resolution of about $0.03^{\circ} \mathrm{C}$ and were operated to measure in 20-min intervals. Because the deployment depth varied slightly over the years the data were vertically interpolated to depths close to the typical thermistor deployment depths. Unfortunately, only in the years 1988, 1989, and 1994 the chains recorded temperatures in the upper $30 \mathrm{~m}$ during the entire winter and spring season, which is the period we examine in this study.

Plankton samples considered in this study were collected weekly during the growing season (less regularly during winter months) at Sta. BM from 1987 to 1994 . Crustacean zooplankton were sampled with a Clarke-Bumpus Sampler (mesh size $140 \mu \mathrm{m}$ ) by vertical hauls from a depth of $140 \mathrm{~m}$. Seven taxa were identified during routine measurements: 
Table 1. Variables and parameter values of the plankton model.

\begin{tabular}{|c|c|c|}
\hline $\mathrm{C}_{\mathrm{Chl} a}$ & $\mathrm{~g}_{\mathrm{Chl} a} \mathrm{~m}^{-3}$ & Concentration of Chl $a$ \\
\hline $\mathrm{C}_{\mathrm{alg}}$ & $\mathrm{g}_{\text {Calg }} \mathrm{m}^{-3}$ & Concentration of algal biomass \\
\hline $\mathrm{Z}^{\text {a }}$ & $\mathrm{g}_{\mathrm{CZ}} \mathrm{m}^{-3}$ & Zooplankton biomass per $\mathrm{m}^{3}$ \\
\hline$\alpha$ & $4.5 \cdot 10^{-3} \mathrm{~m}^{2} \mathrm{~g}_{\mathrm{Calg}} \mathrm{g}_{\mathrm{Chl} a}{ }^{-1} \mathrm{mmol}$ quanta $^{-1}$ & $\begin{array}{l}\text { Photosynthetic efficiency, describing the linear increase of the } \\
\text { specific production with light intensity (PAR in mmol } \\
\text { quanta) }\end{array}$ \\
\hline$P_{\max }^{10}$ & $67.2 \mathrm{~g}_{\mathrm{Calg}} \mathrm{g}_{\mathrm{Chl} a}{ }^{-1} \mathrm{~d}^{-1}$ & Maximum specific production rate at $10^{\circ} \mathrm{C}$ \\
\hline$Q_{10}$ & 2.3 & $\begin{array}{l}\mathrm{Q}_{10} \text { value for the temperature dependence of the maximum } \\
\text { specific production rate }\end{array}$ \\
\hline$\eta_{b}$ & $0.27 \mathrm{~m}^{-1}$ & $\begin{array}{l}\text { Background light attenuation coefficient of algae free water } \\
\text { in Upper Lake Constance }\end{array}$ \\
\hline$k_{\mathrm{Chl} a}$ & $0.021 \mathrm{~m}^{2}\left(\mathrm{mg}_{\mathrm{Chl}}\right)^{-1}$ & Specific light attenuation coefficient of phytoplankton \\
\hline & $0.01 \mathrm{~d}^{-1}$ & Specific base respiration rate \\
\hline$p_{r}$ & 0.2 & Fraction of the production required for respiration \\
\hline$\gamma$ & $0.05 \mathrm{~g}_{\mathrm{Chl} a} \mathrm{~g}_{\mathrm{Calg}}{ }^{-1}$ & Mass Chl a per biomass (carbon) phytoplankton \\
\hline$r_{\text {sed }}$ & $0.1 \mathrm{~m} \mathrm{~d}^{-1}$ & Sedimentation rate of phytoplankton \\
\hline$f_{i}$ & 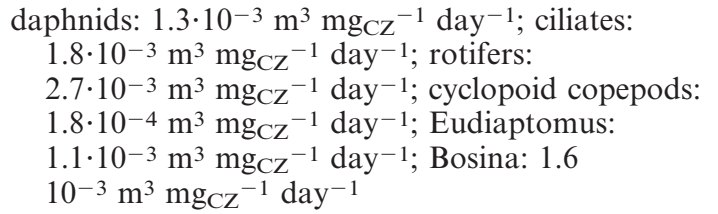 & $\begin{array}{l}\text { Filtering rate of the zooplankton species at } 10^{\circ} \mathrm{C} \text { : water } \\
\text { volume filtered per zooplankton biomass and day }\end{array}$ \\
\hline$Q_{10, i}$ & 2.0 for all zooplanktors & $\begin{array}{l}\mathrm{Q}_{10} \text { value for the temperature dependence of grazing by } \\
\text { zooplankton }\end{array}$ \\
\hline
\end{tabular}

Sources for the parameter values: $\alpha$ and $P_{\max }^{10}$ and $Q_{10}$ for phytoplankton in Upper Lake Constance from Häse (1996); Tilzer (1988) provides values for $\eta_{b}$ and $k_{\mathrm{Chl} l}$, which were both specifically determined for Upper Lake Constance; Geider and Osborne (1989) give a parameter range for $p_{r}$ from 0.1 to 0.7 and for $b_{r}$ from $0 \mathrm{~d}^{-1}$ to $1 \mathrm{~d}^{-1}$. Sommer (1984) estimated sedimentation rates $r_{\text {sed }}$ ranging from 0.033 to $1.6 \mathrm{~m} \mathrm{~d}^{-1}$ for nine algae species in Upper Lake Constance. The lowest value is for Stephanodiscus hantzschii, which is very common in spring. Zooplankton filtering rates were calculated on the basis of values from different sources: for daphnids, Eudiaptomus, and rotifers from the corresponding mean values given by Jürgens et al. (1996); for ciliates from mean values published by Weisse et al. (2001); for cyclopoid copepods from values by Santer and van den Bosch (1994). The filtering rate given of Bosmina given by Jürgens et al. (1996) was very high. We chose a value in between Daphnia and ciliates to account for allometric relationships.

Daphnia hyalina, Daphnia galeata, Bosmina sp., Eudiaptomus gracilis, cyclopoid copepods, Leptodora kindtii, and Bythotrephes longimanus (Straile and Geller 1998). The individual taxa were separated into up to five size classes. Biomass was calculated from length-dry-weight relationships established for Upper Lake Constance. Here we consider the (potentially) herbivorous taxa Daphnia, Bosmina, E. gracilis, and cyclopoid copepods. Chlorophyll $a(\mathrm{Chl} a)$ was sampled at distinct depths between 0 to $60 \mathrm{~m}$, analyzed spectrophotometrically after extraction in hot ethanol, and corrected for pheopigments by acidification (Häse et al. 1998). Ciliates and rotifers were counted in mixed samples from $0-8-\mathrm{m}$ and $8-20-\mathrm{m}$ depths. Abundances were converted into biomass according to the methods described by Weisse and Müller (1998) and Pauli (1989).

Phytoplankton model - The phytoplankton model considers production and loss of Chl $a$ in a one-dimensional (1D) vertical water column with transport by advection and turbulent diffusion. Model parameters are summarized in Table 1. Phytoplankton growth is simulated considering production according to the Blackman equation (Blackman 1905):

$$
P=\min \left(\alpha \cdot I, P_{\max }(T)\right)
$$

where $P$ is the specific production rate and the gross biomass production is proportional to the $\mathrm{Chl} a$ concentration, $C_{\text {Chla }} . P$ increases linearly with light intensity $I$ (photosynthetically active radiation $[\mathrm{PAR}]$ in mol quanta $\mathrm{m}^{-2} \mathrm{~s}^{-1}$ ) until light limitation limits production to a maximum specific production rate $P_{\max }(T)$. The linear increase of the specific production with light intensity is described by $\alpha$. $T$ represents water temperature in ${ }^{\circ} \mathrm{C}$. The temperature dependence of $P_{\max }$ is modeled using a $Q_{10}$ approach

$$
P_{\max }(T)=P_{\max }^{10} \cdot Q_{10}^{(T / 10-1)}
$$

with a maximum specific production rate at $10^{\circ} \mathrm{C}$ of $P_{\max }^{10}=2.8 g_{C} \cdot g_{\mathrm{Chl} a}^{-1} \cdot h^{-1}$ and a $Q_{10}$ of $Q_{10}=2.3$ (Häse 1996). Results did not significantly depend on the specific form of the photosynthesis-irradiance curve; the use of the hyperbolic tangent equation (Jassby and Platt 1976), for example, produced a very similar phytoplankton development as the Blackman equation. In the following we present the simulation results obtained with the Blackman equation because this allows a simple separation between light- and temperature-controlled growth of phytoplankton. Inhibition of production at high light intensities is assumed to be unimportant during winter and spring conditions. Light intensity as a function of depth $z$ is estimated on the basis of light attenuation according to Beer's law:

$$
\frac{d I}{d z}=-\eta(z) \cdot I \Rightarrow I(z)=I_{o} \cdot e^{-\int_{0}^{z} \eta(z) d z}
$$


and $I o$ is the light intensity (PAR) entering the water column at the lake surface. $I o$ is time-dependent and has been calculated from measured solar radiation considering time variable reflection from the lake surface due to the changing angle of the incident light. The angle of the incident light was calculated from declination, latitude, and solar time. The proportion of reflected light was calculated from the Fresnels equations using an index of refraction of 1.33 (Palmer and Williams 1974). Io has been calculated from solar radiation values $S\left(\mathrm{~W} \mathrm{~m}^{-2}\right)$ using $I_{o}(\mathrm{mmol}$ quanta $\left.\mathrm{m}^{-2} \mathrm{~s}^{-1}\right)=2.11 \cdot 10^{-3} S\left(\mathrm{~W} \mathrm{~m}^{-2}\right)$ (Häse 1996 citing Bannister 1974).

The light attenuation coefficient $\eta(z)$ is calculated following the method described by Tilzer (1988) as:

$$
\eta(z)=\eta_{b}+k_{\mathrm{Chl} a} \cdot C_{\mathrm{Chl} a}(z)
$$

where $\eta_{b}$ describes the background light attenuation of algae free water in Upper Lake Constance due to light absorption by water and dissolved substances, and $k_{\mathrm{Chl} a}$ is the specific light attenuation coefficient of the phytoplankton.

The net biomass production (NBP) as a function of depth is calculated from

$$
\operatorname{NBP}(z)=P(\mathrm{z}) \cdot C_{\mathrm{Chl} a}(z)-R(\mathrm{z})
$$

where $R(z)$, the respiration rate, has been modeled considering two contributions: a specific base respiration rate, $b_{r}$, during light and dark time periods and an additional respiration rate proportional to production (e.g., Geider and Osborne 1989)

$$
R(\mathrm{z})=b_{r} \cdot C_{\mathrm{alg}}(z)+p_{r} \cdot P(z) \cdot C_{\mathrm{Chl} a}(z)
$$

where $C_{\mathrm{alg}}$ is the concentration of algal biomass and $p_{r}$ is the fraction of production lost by respiration. The calculation of net production from light intensities (and temperatures) provides the biomass (carbon) phytoplankton produced per unit time. The Chl $a$ concentration is estimated from the algae biomass assuming a fixed ratio of $\gamma=$ $0.05 \mathrm{~g}_{\mathrm{Chl} a} \cdot \mathrm{g}_{\mathrm{Calg}}{ }^{-1}$.

In all simulations the parameters of the plankton model including respiration rates, carbon to Chl $a$ ratio, and the maximum specific production rate at $10^{\circ} \mathrm{C}$ were kept constant in time (i.e., neither seasonal nor annual changes in the parameters were considered). Keeping the parameter values fixed in time has the disadvantage that light acclimation and changes in community structure cannot be included. However, keeping the parameters fixed may reveal the relevance of a change in parameter values over time on phytoplankton biomass and thus can be used to identify the most important processes that should be included in an extended model.

In addition to production and respiration we have included loss of phytoplankton biomass due to grazing by different zooplankton species using a first-order functional response with a simple $Q_{10}$ approach describing temperature dependence. The total change of $\mathrm{Chl} a$ per unit time due to biological processes (i.e., the source of $\mathrm{Chl}$ $a$ concentration, $S_{\mathrm{Chl} a}$ ) is given by:

$S_{\mathrm{Chl} a}=\left\{\gamma \cdot P\left(1-p_{r}\right)-b_{r}-\sum_{i} Q_{10, i}^{\left(T / 10^{\circ} C-1\right)} f_{i} \cdot Z_{i}\right\} \cdot C_{\mathrm{Chl} a}(7)$

where $Z_{i}$ is the zooplankton abundance of species $i$, and $f_{\mathrm{i}}$ and $Q_{10, i}$ are the corresponding filtering rate and the $Q_{10}$ value, respectively. $T$ is the water temperature in ${ }^{\circ} \mathrm{C}$. Ciliates, rotifers, cyclopoid copepods, Eudiaptomus, Bosmina, and daphnids are considered as herbivores in the model. All these taxa feed on phytoplankton at least during certain stages of their ontogenetic development; however, some species (of ciliates and rotifers) or some ontogenetic stages (of Eudiaptomus and cyclopoid copepods) also feed on zooplankton. The zooplankton abundance is not simulated dynamically but is taken from the data set. In the model the vertical distribution of all zooplankton species $Z_{i}(z)$ is estimated by assuming that for each species the relative zooplankton biomass in the vertical profile is proportional to the relative concentration of the simulated Chl $a$ in the vertical profile (for the depth region between $\mathrm{a}$ and $\mathrm{b}$ )

$$
Z_{i}(z)=\frac{C_{\mathrm{Chl} a}(z)}{\int_{a}^{b} C_{\mathrm{Chl} a}\left(z^{\prime}\right) d z^{\prime}} \cdot Z_{i, \mathrm{data}}
$$

For daphnids, cyclopoid copepods, Eudiaptomus, and Bosmina the measured biomass $Z_{i}$, data is assumed to stem from the top $20 \mathrm{~m}$, which is motivated by the depthresolved measurements in Upper Lake Constance during May by Geller (1986). For ciliates and rotifers the two sampled depth regions from $0-8 \mathrm{~m}$ and $8-20 \mathrm{~m}$ are considered independently. For depths below $20 \mathrm{~m}$ the ciliate and rotifer abundance is estimated by assuming that the ratio of phytoplankton to ciliate and rotifer biomass, respectively, is the same as in the $8-20-\mathrm{m}$ depth region; that is,

$$
Z_{i}(z)=C_{\mathrm{Chl} a}(z) \cdot \int_{8}^{20}\left(Z_{i}\left(z^{\prime}\right) / C_{\mathrm{Chla}}\left(z^{\prime}\right)\right) d z^{\prime}
$$

for ciliates and rotifers below $20 \mathrm{~m}$.

Vertical transport of algae due to turbulent and convective water motions is simulated by turbulent diffusivities because it is common practice in 1-D transport models (e.g., Omlin et al. 2001b; Huisman et al. 2002). Sinking of algae is included as an advective component in the 1-D vertical transport equation:

$$
\frac{\partial C_{\mathrm{alg}(z)}}{\partial t}=\frac{\partial}{\partial z}\left\{K_{z} \frac{\partial C_{\mathrm{alg}}(z)}{\partial z}\right\}-v_{\mathrm{sed}} \frac{\partial C_{\mathrm{alg}}}{\partial z}+S_{\mathrm{alg}}
$$

and $S_{\text {alg }}$ is a source of concentration of algae biomass $C_{\text {alg }}$ per unit time calculated from Eq. 7 by dividing $S_{\mathrm{Chl} a}$ by $\gamma$. The sinking velocity of algae is $v_{\text {sed }}$, and $K_{z}$ is the turbulent 
diffusivity. The transport model requires vertical profiles of turbulent diffusivities and temperatures as function of time. These parameters are calculated from the 1-D model SIMSTRAT (Goudsmit et al. 2002; Peeters et al. 2002), which is based on a $k-\varepsilon$ model. SIMSTRAT uses hourly measurements of the meteorological variables wind speed, wind direction, solar radiation, air temperature, cloud cover, and humidity to calculate dynamic changes in turbulent kinetic energy $(k)$, energy dissipation $(\varepsilon)$, and thermal stratification. Profiles of vertical turbulent diffusivities are determined from the estimates of $k$ and $\varepsilon$. Temperature profiles are calculated on the basis of heat exchange at the lake surface and on the transport of heat by turbulent diffusion. Heat exchange is simulated from empirical relations considering the heat flux due to longand short-wave radiation, evaporation, and heat conduction. For details on the processes considered in SIMSTRAT and on their mathematical formulation see Goudsmit et al. (2002).

Model operation and numerical implementation-SIMSTRAT and the phytoplankton model are operated independently. The only feedback of the biology on the lake dynamics and the thermal structure is via the light attenuation coefficient, which depends on phytoplankton density. Monthly mean phytoplankton concentrations were calculated as a function of depth on the basis of phytoplankton data. The monthly values from the different years were averaged to provide a mean year of depthresolved monthly mean phytoplankton concentrations. The latter were used to calculate the light attenuation coefficients for SIMSTRAT.

SIMSTRAT has been calibrated for the conditions of Upper Lake Constance by adjusting five constant parameters using the same procedure as in the study on Lake Zürich by Peeters et al. (2002). The adjusted parameters are constant factors that scale the heat flux by long-wave radiation, the latent heat flux, the transfer of momentum from the atmosphere to lake water, the transfer of wind energy to seiche energy, and the distribution of energy loss from the seiching motion. The calibration is required because meteorological data, and especially wind conditions measured at a shore station, are not representative of the entire lake. The calibration period covered the years from 1979 to 1984 and parameter optimization was based on a comparison of simulated temperature profiles to the temperature profiles measured monthly to biweekly at Sta. $\mathrm{C}$ (Fig. 1). SIMSTRAT is implemented in FORTRAN (for details, see Goudsmit et al. 2002). SIMSTRAT was operated with a time step of $10 \mathrm{~min}$ and a vertical resolution of $0.25 \mathrm{~cm}$.

As driving parameters for the phytoplankton model, hourly profiles of temperature and turbulent diffusivities with a vertical resolution of $1 \mathrm{~m}$ were calculated from SIMSTRAT. In all simulations SIMSTRAT was initialized for 1979 and run in a continuous fashion to provide predictions of the vertical distribution of temperature and turbulent diffusivities for the years 1987 to 1994.
The numerical technique employed to solve the 1-D phytoplankton model is similar to the methods used by Omlin et al. (2001b) and Huisman et al. (2002). The phytoplankton model is implemented in MATLAB and is based on the method of lines. The advection equation is discretized using a Van-Leer flux-limiter method, which is a nonlinear technique mixing first-order and second-order discretization to minimize numerical diffusion. The entire system of coupled ordinary differential equations is solved by an implicit method. The size of the time step is adjusted dynamically. The effect of the phytoplankton concentration on the light intensities is not considered in the Jacobian matrix but included explicitly.

The phytoplankton model has a vertical resolution of $0.25 \mathrm{~m}$ and was operated discontinuously because the summer months are beyond the scope of the model. Each year, the phytoplankton model was initialized at the first of January with the initial profile calculated from the measured Chl a concentration by linear interpolation. The physical conditions water temperature and turbulent diffusion were taken from SIMSTRAT and interpolated linearly to the appropriate depths and times required in the phytoplankton model. Solar radiation was obtained from the meteorological data set. Zooplankton biomass as a function of time was taken from the data and also interpolated linearly to the times required in the model.

\section{Results and discussion}

Comparison of the simulated temperature stratification with data-Temperatures simulated by SIMSTRAT agree very well with the observed high temporal resolution temperatures from the thermistor chains at Sta. BM (Fig. 2). Note that the model was calibrated with data from Sta. $\mathrm{C}$ and that the simulations agree very well with the temperature data from both stations $\mathrm{C}$ and $\mathrm{BM}$, suggesting that horizontal temperature differences are small. The model adequately predicts not only the seasonal temperature development (Fig. 2A,B), but also the onset of the thermal stratification during spring conditions (Fig. 2C-H). Even the inverse stratification in 1987 (Fig. 2C-D) is predicted by the model. Note that the simulations have been performed in a continuous fashion, that the calibration period extended only until 1984, and that the simulated thermal stratification is a prediction of a model run that was initialized in 1979. The higher frequency fluctuations in the temperature data are the result of the vertical displacement of the isotherms due to internal wave motion and especially by seiching (Bäuerle et al. 1998). SIMSTRAT does not resolve internal wave dynamics, because this is impossible in a 1-D model, but considers empirically the energy fluxes due to seiching as a source term for turbulent kinetic energy and dissipation (Goudsmit et al. 2002).

The excellent agreement between simulation and data is surprising because 1-D hydrodynamic models principally cannot adequately represent the dynamic behavior and the mixing conditions in lakes. Production of turbulent kinetic energy and dissipation depend on 3-D processes generating velocity shear by, for example, friction at the lake 

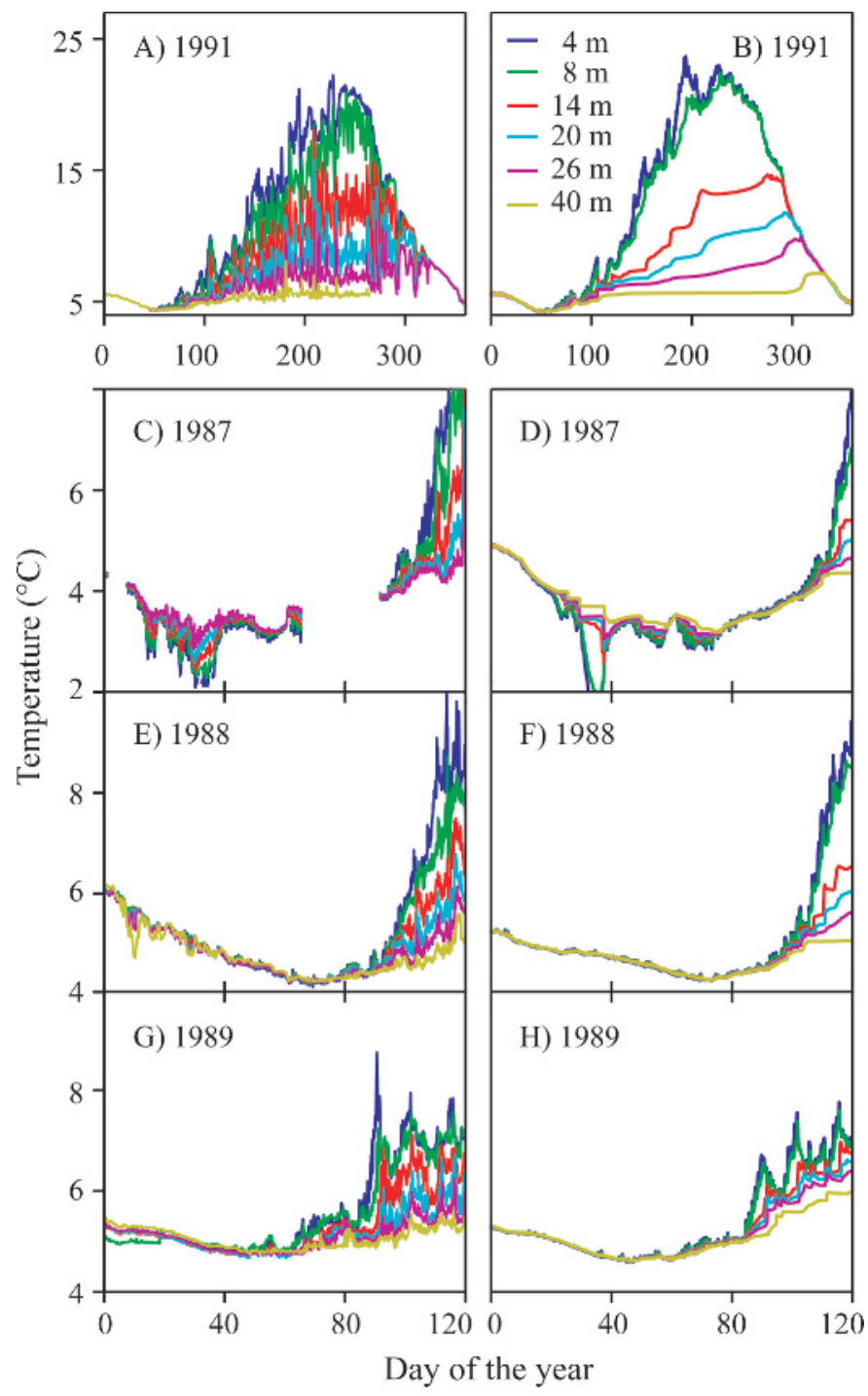

Fig. 2. Comparison of measured and simulated water temperatures. (A, C, E, G) Temperatures measured with thermistors. (B, D, F, H) Model results. Panels A and B depict a full season in 1991, whereas panels $\mathrm{C}-\mathrm{H}$ show winter and spring seasons in more detail for the years 1987 to 1989. Data were averaged over $12 \mathrm{~h}$ in $(\mathrm{A})$ and over $2 \mathrm{~h}$ in $(\mathrm{C}, \mathrm{E}$, and $\mathrm{G})$.

boundaries or by seiche motion, which is strongly affected by lake morphometry. Such processes can only be included empirically in 1-D models. Nevertheless, in many studies, different 1-D hydrodynamic models have been demonstrated to successfully describe thermal stratification in lakes (e.g., Robertson and Ragotzkie 1990; Stefan et al. 1998; Peeters et al. 2002) suggesting that the underlying model structure resembles the dynamic behavior of lakes sufficiently well.

Simulated temperature stratification and the onset of the phytoplankton growth - In winter and spring the mean measured Chl $a$ concentration in the top $20 \mathrm{~m}$ is very well correlated with the water temperature difference between 0 and $40 \mathrm{~m}\left(\Delta \mathrm{T}_{40}\right.$; Fig. 3$) . \Delta \mathrm{T}_{40}$ can be considered as

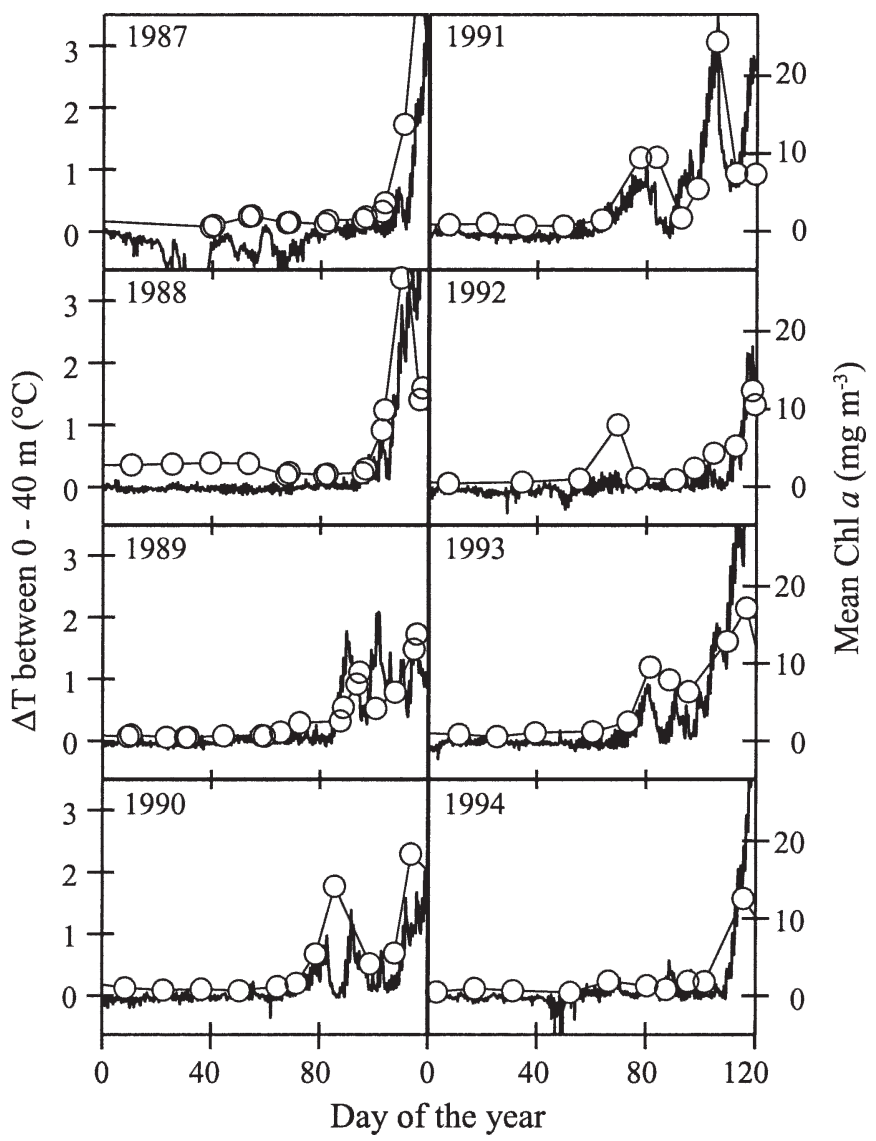

Fig. 3. Thermal stratification and phytoplankton development in winter and spring. The mean concentration of measured Chl $a$ in the top $20 \mathrm{~m}$ (circles) increases as soon as the temperature difference between a depth of 0 and $40 \mathrm{~m}$ calculated from the physical model (line) reaches values of about $1{ }^{\circ} \mathrm{C}$.

a measure of thermal stratification within the upper $40 \mathrm{~m}$. The basis of Fig. 3 is simulated temperatures because the temporal resolution of the long-term data set is insufficient and the measurements with high temporal resolution are not always available in spring. Apparently, the onset of phytoplankton growth occurs as soon as $\Delta \mathrm{T}_{40}$ exceeds about $1{ }^{\circ} \mathrm{C}$ only. Because the development of such slight temperature stratification is highly dependent on the meteorological forcing, the onset and early development of the spring phytoplankton bloom is very sensitive to the environmental conditions prevailing during winter and spring. In addition to the strong coherence between the first increase in $\Delta \mathrm{T}_{40}$ and in Chl $a$, the decline in Chl $a$ after the initial increase that occurred (e.g., in the years 1990, $1991,1993)$ is accompanied by a decrease in $\Delta \mathrm{T}_{40}$ to values close to $0^{\circ} \mathrm{C}$, suggesting that mixing as indicated by the reduced stratification is important for algal development also in time periods after the onset of phytoplankton growth.

Comparison of the phytoplankton model with data-The phytoplankton model was initialized each year at the first of January. During the first $50 \mathrm{~d}$ of each year (not shown in Fig. 4) the phytoplankton population manages to persist at 
about a constant level, in agreement with the data. In the $8 \mathrm{yr}$ investigated in this study the phytoplankton model, considering production and respiration but ignoring losses due to predation (Fig. 4, blue line), we can adequately predict the onset of phytoplankton growth indicated by the timing of the initial increase in Chl $a$ (Fig. 4). The only exception is the first minor peak in Chl $a$ in 1992, which is not predicted by the model. The discrepancy between simulated and measured Chl $a$ in March 1992 is possibly due to the physical model, which does not predict a significant change in the mixing conditions at that time.

After the initial increase, the Chl $a$ concentration simulated without predation exceeds the observed Chl $a$, suggesting that additional processes must be included to adequately simulate phytoplankton loss. However, the observed interannual variation in the timing of the onset of the phytoplankton growth is excellently reproduced by the simple hydrodynamically driven phytoplankton model. In agreement with the data, the simulations indicate that the onset of the algal bloom is earlier in the 1989, 1990, 1991, and 1993 than in 1987, 1988, and 1994. The above results suggest that rather simple irradiance-growth models are sufficient to accurately predict the start of the spring bloom (sensu Flynn 2003), and that predation by zooplankton is unimportant for the timing of the initial phytoplankton growth.

The role of zooplankton in phytoplankton losses-Including predation by Daphnia has a negligible effect on the model results up to d 120 of each year. Daphnia biomass starts to increase strongly from the end of April onward (Straile 2000). Up to d 120, Daphnia biomass in Upper Lake Constance is one to two orders of magnitude lower than the biomass of, for example, ciliates (Gaedke and Straile 1994). Because the specific filtration rate of daphnids is also lower than that of the ciliates, daphnids do not have a significant effect on phytoplankton development in winter and early spring (e.g., before the clearwater phase).

Ciliate development closely follows phytoplankton biomass (Fig. 4, symbols) (Müller et al. 1991). Early in the season the ciliate biomass is very low. In each year the first substantial increase in ciliate biomass occurs almost simultaneously with the increase in Chl $a$ (Müller et al. 1991). Therefore, including grazing by ciliates in the phytoplankton model only slightly affects the $\mathrm{Chl} a$ concentration during the first months of a year until the first increase in Chl $a$ (Fig. 4, black line). After the initial increase in $\mathrm{Chl} a$, ciliate grazing significantly reduces the phytoplankton abundance, thereby improving the agreement between data and simulations in most years. The dominant ciliates during this time of the year are small raptorial algal feeders such as Balanion and Urotricha (Carrias et al. 2001; Weisse et al. 2001). We used the low clearance rates obtained for these raptorial species (Weisse et al. 2001) in our calculations. Despite the rather low specific clearance rate, ciliates dominated phytoplankton grazing. This is consistent with the results from several studies investigating the role of protozoans in Upper Lake Constance (Weisse et al. 1990; Gaedke and Straile 1994;

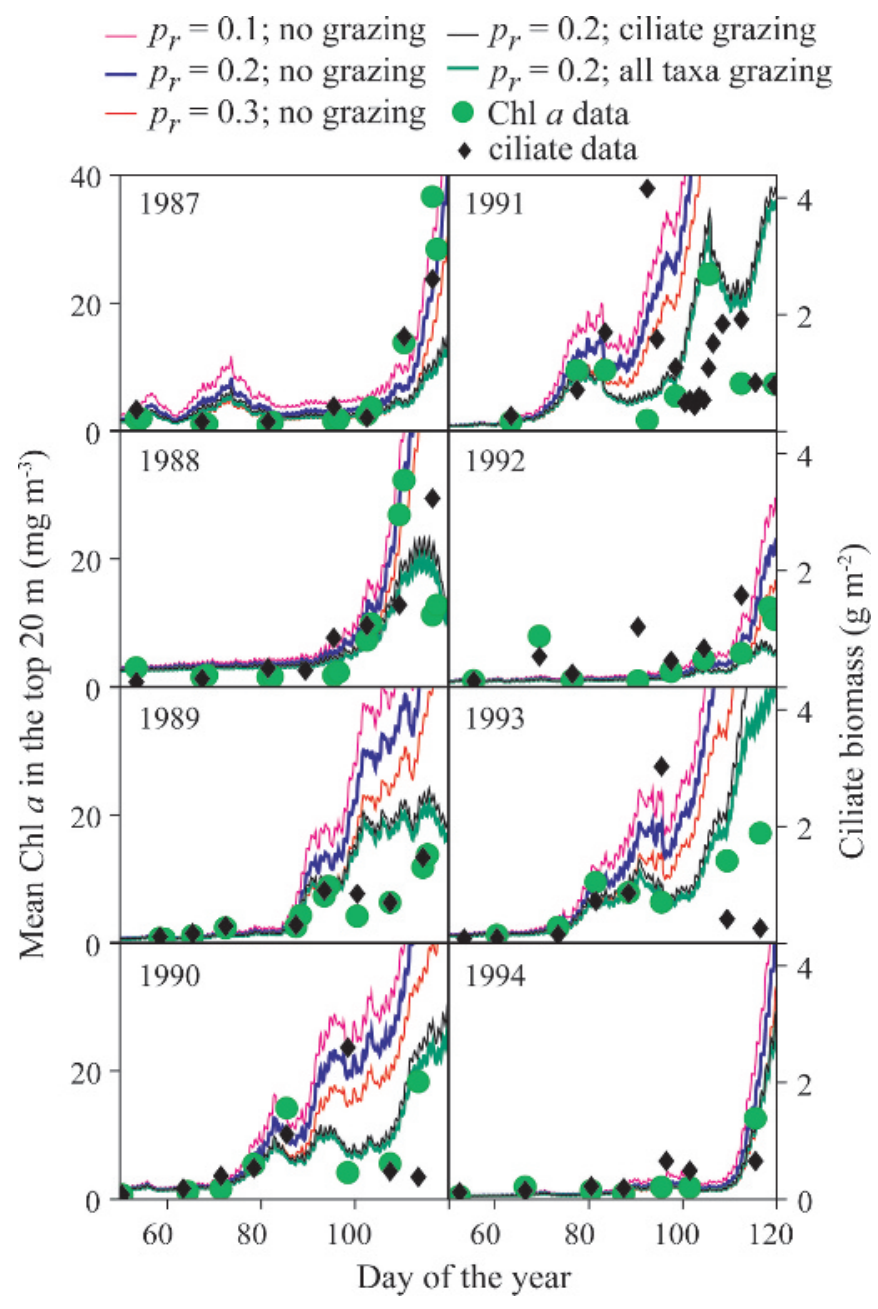

Fig. 4. Validation of the phytoplankton model and sensitivity analysis with respect to model parameters and zooplankton predation. The different panels compare data and model results for the years 1987 to 1994. Green symbols represent the mean concentration of measured $\mathrm{Chl} a$ in the top $20 \mathrm{~m}$. Magenta, blue, and red lines correspond to model runs without considering zooplankton predation assuming respiration parameter $p_{r}$ to be $0.1,0.2$, and 0.3 , respectively. Black symbols represent ciliate biomass measured in the top $20 \mathrm{~m}$. Black and green lines show results from simulations with predation by ciliates (black line) and by all zooplankton taxa (green line). In these simulations $p_{r}=0.2$.

Tirok and Gaedke 2006), other lakes (Carrias et al. 2001) and marine environments (Strom et al. 2001; Leising et al. 2005). In 1987 and 1988, when Chl $a$ concentrations were high, ciliate grazing in the model reduced Chl $a$ to values even below observations. Apparently, at high algae concentrations the model overestimates ciliate grazing, which could be the result of the simple first-order functional response assumed in the model that does not include a saturation of feeding rates with increasing food concentration.

Other zooplankton taxa (rotifers, cyclopoid copepods, Eudiaptomus, and Bosmina) also cause phytoplankton losses that may significantly affect the total phytoplankton biomass in the spring of specific years. However, including these zooplankton species and daphnids in 
addition to ciliates has no additional effect on the phytoplankton biomass in winter and early spring (Fig. 4, green line). The above analysis indicates that in Upper Lake Constance during the first $120 \mathrm{~d}$ of each year, ciliates are the most important grazers feeding on phytoplankton. Additionally, it shows that ciliate filtration, photosynthesis, and respiration result in a net phytoplankton growth that leads to a phytoplankton development consistent with the data.

Sensitivity of phytoplankton growth to model parametersThe most uncertain parameters of the phytoplanktonzooplankton model are the two parameters related to respiration and the filtering rates describing zooplankton grazing. Because these parameters are all related to phytoplankton loss, they are correlated in their effect on the Chl $a$ concentration. Simulations obtained with the parameter combination $b_{r}=0.02 \cdot \mathrm{d}^{-1}$ and $p_{r}=0.1$ are essentially the same as those using the parameter combination $b_{r}=0.01 \cdot \mathrm{d}^{-1}$ and $p_{r}=0.2$ (Fig. 4, blue line). The close agreement between the simulations indicates that the values of $b_{r}$ and $p_{r}$ describing respiration cannot be identified independently on the basis of the data. The sensitivity of the model to the choice of different $p_{r}$ is demonstrated in Fig. 4 ( $p_{r}=0.1$ : magenta, $p_{r}=0.2$ : blue, and $p_{r}=0.3$ : red line). With increasing $p_{r}$, overall phytoplankton loss increases and the predicted Chl $a$ concentration is reduced. In these simulations, $b_{r}=$ $0.01 \mathrm{~d}^{-1}$, and grazing is not considered. Because grazing additionally increases phytoplankton loss, the parameter sets with high respiration are considered to be inappropriate. In the simulations with zooplankton grazing included (Fig. 4, black and green lines) we used $b_{r}=0.01 \mathrm{~d}^{-1}$ and $p_{r}$ $=0.2$. The same respiration parameters will be employed from here on.

Another uncertain parameter in the phytoplankton model is $\gamma$ describing the $\mathrm{Chl} a$ to carbon ratio. Because $\gamma$ is a scaling factor to convert production of carbon to production of Chl $a$, the effects of changes in $\gamma$ and changes in the respiration parameter $p_{r}$ are correlated. More specifically, $\gamma$ and $p_{r}$ cannot be identified independently, because the production-dependent source term of Chl $a$ in Eq. 7 can be written as: $\gamma \cdot\left(1-p_{r}\right) \cdot P=a_{1} \cdot P$ with $a_{1}=\gamma$ $-\gamma \cdot p_{r}$. Hence, increasing the Chl $a$ to carbon ratio from $1: 20$ to $1: 15$, for example (i.e., increasing $\gamma$ from 0.050 to $0.067)$, has the same effect on the Chl $a$ production rate as increasing $p_{r}$ from 0.2 to 0.4 .

In contrast to the variation arising from the uncertainty of the parameters discussed above, changes in the sinking velocity of the phytoplankton has a small effect on phytoplankton abundance. In all simulations of Fig. 4 we assumed a sinking velocity of $0.1 \mathrm{~m} \mathrm{~d}^{-1}$. Increasing the sinking velocity by one order of magnitude to $1.0 \mathrm{~m} \mathrm{~d}^{-1}$ results in simulated $\mathrm{Chl} a$ concentrations that agree very closely with the red line in Fig. 4 (i.e., it leads to the same reduction in $\mathrm{Chl} a$ as increasing the respiration parameter, $p_{r}$, from 0.2 to 0.3 ).

Besides the parameters describing properties of phytoplankton, filtering rates for the different zooplankton taxa in the zooplankton model are rather uncertain. As mentioned above, filtering rates and respiration parameters are correlated in their effect on Chl $a$ concentrations. Decreasing the filtering rate of ciliates by $50 \%$ and using $p_{r}$ $=0.2$ leads to a phytoplankton development that hardly differs from a simulation with the original filtering rate and $p_{r}=0.1$. Even more severe, similar model results, at least up to the first 3 weeks after the onset of phytoplankton growth, are obtained if zooplankton grazing is ignored altogether but the respiration parameter is increased to $p_{r}$ $=0.3$. Thus, the relative importance of ciliate grazing and respirational losses described by $p_{r}$ is significantly affected by the parameter values assumed in the model. Note also that the relative magnitude of the filtering rates for the different zooplankton taxa affects the relative importance of the taxa for the grazing of phytoplankton. However, because the biomass of all zooplankton taxa except ciliates is rather low during the time period investigated, ciliates remain the dominant grazers in our study if reasonable filtering rates are assumed.

Sensitivity of phytoplankton growth to environmental conditions - The sensitivity of the phytoplankton model to the environmental conditions is exemplified for 1988 and 1990. The timing of the onset of phytoplankton growth differed substantially between these years because it is indicated by the data (circles in Fig. 5A,B) and the reference simulation (Fig. 5A,B, blue solid line). The reference simulation corresponds to the model run represented by the blue line in Fig. 4 and is based on the measured solar radiation and the temperatures and turbulent diffusivities simulated with SIMSTRAT. Zooplankton grazing is not considered because it does not affect the timing of the onset of phytoplankton growth (see above). The individual effects of irradiance, water temperature, and turbulence on phytoplankton growth are studied by changing one forcing variable and keeping the others to those of the reference simulation (i.e., to the observed irradiance and to the water temperature and turbulent diffusivity derived from SIMSTRAT).

The relevance of annual differences in the solar radiation for phytoplankton growth is investigated by averaging the hourly time series for the first $120 \mathrm{~d}$ of 1988 and 1990 to obtain an average day of hourly values of solar radiation. Chl $a$ is then simulated by using this average day of hourly solar radiation values repeatedly for all days in the simulation. Water temperatures and diffusivities are the same as in the reference simulation. The model results on Chl a obtained with the constructed solar radiation values (Fig. 5A,B, light green line) differ very little from he reference model based on measured solar radiation (Fig. 5A,B, blue line), indicating that the direct effects of interannual variations in solar radiation on photosynthesis are not responsible for the interannual variations in the timing of phytoplankton growth. This finding from Upper Lake Constance differs from the modeling results by Tian et al. (2003a) where seasonal variation in solar radiation has been identified as a dominant cause of the onset of phytoplankton blooms in coldocean environments. Even if we drive our model by repeatedly using the February average daily course of solar 


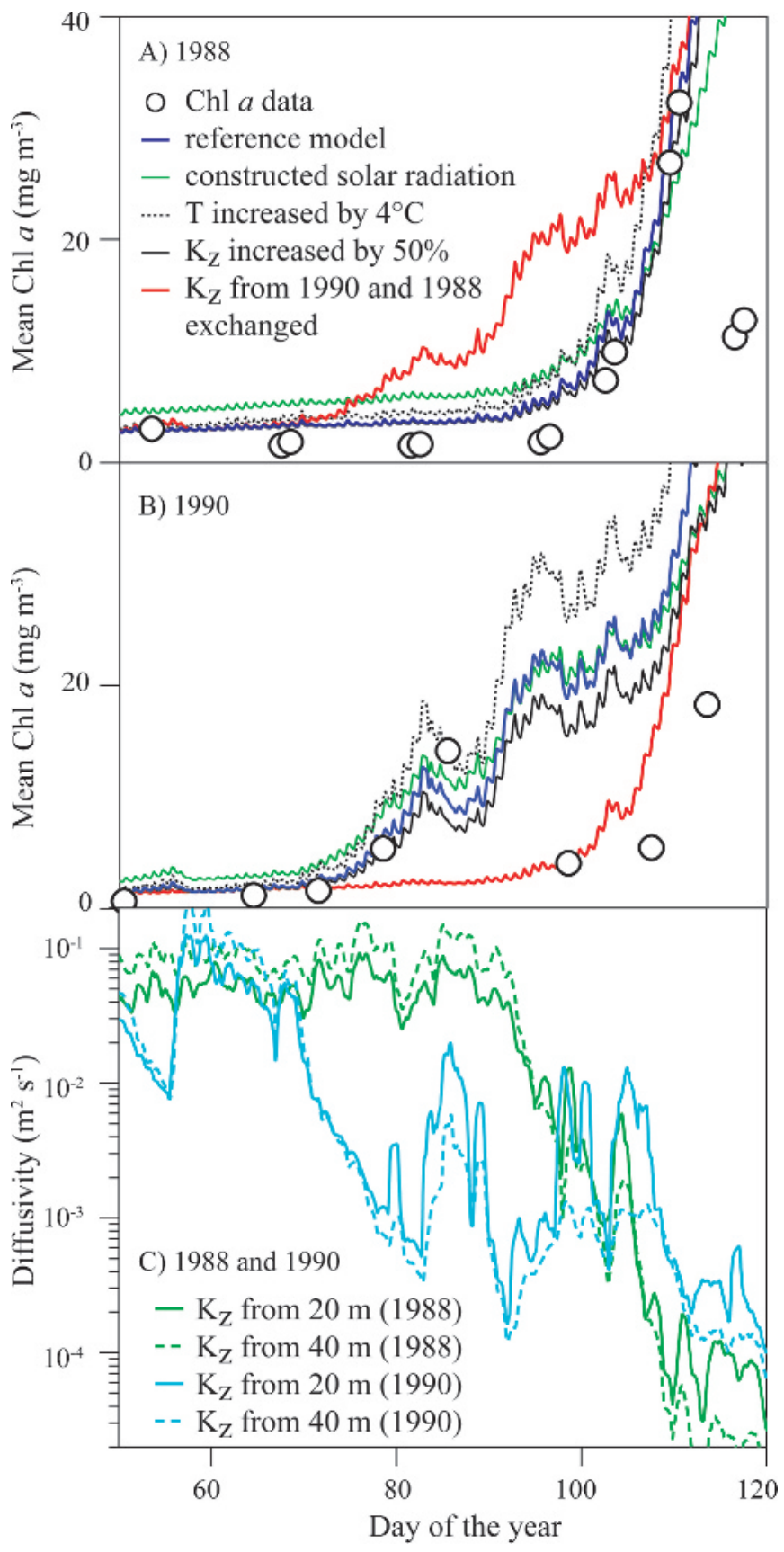

Fig. 5. The role of environmental conditions for the timing of phytoplankton growth. (A, B) Model results for Chl $a$ development from simulations assuming different physical conditions are compared with the mean concentration of measured $\mathrm{Chl}$ $a$ in the top $20 \mathrm{~m}$ for 1988 and 1990 . The reference simulation is designed on the basis of temperatures and diffusivities calculated from SIMSTRAT and solar radiation determined from data. It corresponds to the blue line in Fig. 4 and does not consider predation. Model runs based on a mean day of hourly solar radiation values, temperature increase of $4{ }^{\circ} \mathrm{C}$, and diffusivity increase by $50 \%$ do not differ significantly from the reference model. Using diffusivities from 1990 to drive the model in 1988 and vice versa leads to a significant change in simulated Chl $a$. (C) The diffusivities from water depths of $20 \mathrm{~m}$ and $40 \mathrm{~m}$ for 1988 and 1990. Note the logarithmic scale in (C). radiation until May, the timing of the plankton blooms is not significantly affected, but only the phytoplankton growth after the onset of the phytoplankton bloom. The low solar radiation intensity from February is sufficient to support a phytoplankton bloom, a conclusion that is consistent with observations from Lake Zurich demonstrating that phytoplankton can start to develop early in the season at very low radiation values (Bleiker and Schanz 1997).

The underwater light climate depends not only on solar radiation but also on the light attenuation in the water column. According to our model, an increase in the background light attenuation coefficient of algae free water, $\eta_{b}$, results in a delay of the onset of phytoplankton growth followed by a weaker increase in the phytoplankton population compared with the reference situation. Both consequences of increased $\eta_{b}$ are in accordance with expectation because a larger $\eta_{p}$ implies a shallower depth of the photic zone and a reduction in the light intensity available for photosynthesis in the top $20 \mathrm{~m}$ of the water column. However, to generate a variation in the onset of phytoplankton growth that is similar to the interannual variation observed in the data, $\eta_{b}$ must change from year to year by more than a factor of two. Such a large variability in $\eta_{b}$ may occur in specific coastal systems but not in Lake Constance, where the light attenuation coefficient $\eta$ from different years varies by less than $20 \%$ at low Chl $a$ concentrations (Tilzer 1983).

The direct effect of the interannual and intra-annual variations in water temperature and vertical temperature distribution on phytoplankton growth in spring is even smaller than the direct effect of the variation in solar radiation as long as the mixing conditions do not change. Using the same turbulent diffusivities as in the reference simulation but assuming that the water temperature is $5^{\circ} \mathrm{C}$ at all times and all depths results in almost the same simulated Chl $a$ concentration as predicted by the original model considering time and depth varying temperatures. The difference between the simulations is about the same as the line thickness in Fig. 5A,B. Note that the comparison between the two simulations demonstrates the sensitivity of the biological model to water temperature under the same dynamic conditions because in both simulations the same turbulent diffusivities were employed. The $5^{\circ} \mathrm{C}$ chosen above corresponds to the mean temperature in the top $40 \mathrm{~m}$ of Upper Lake Constance averaged over the first $120 \mathrm{~d}$ of 1987 to 1994.

According to the Blackman equation, water temperature affects the phytoplankton growth rate only via the level of the maximum specific production rate, $P_{\max }$. Hence, production is limited by temperature only if the light intensity is sufficient to result in maximum production $P_{\max }$. The shaded area in Fig. 6 indicates the depth region where phytoplankton growth is limited by temperature. Apparently, the depth region of temperature limitation of phytoplankton growth in winter and spring is larger than in summer. If water temperature is constant, the increase in solar radiation from winter to summer should cause a deepening of the zone of temperature limitation. However, the increase in temperature and its effect on 


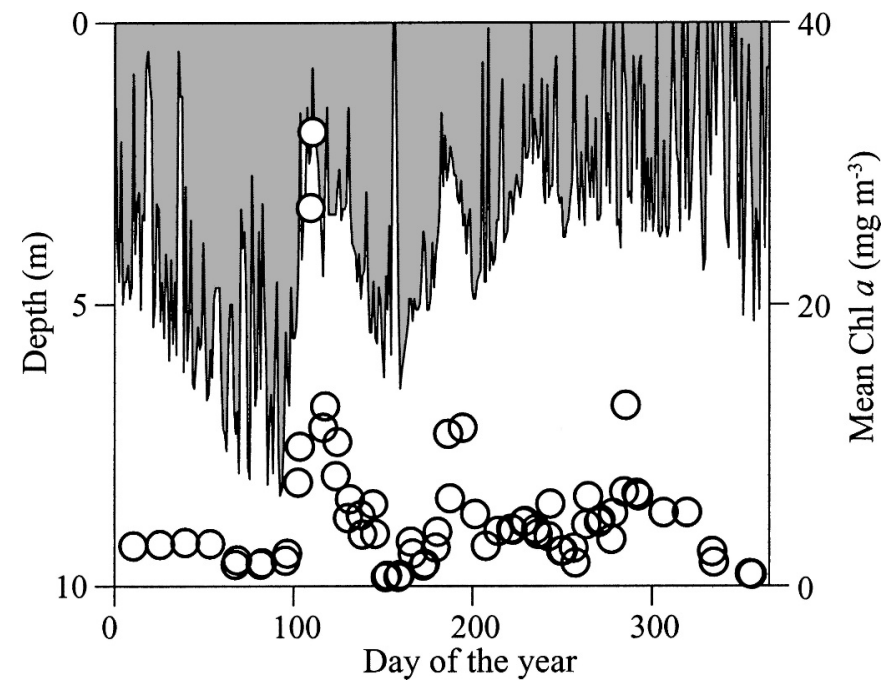

Fig. 6. Temperature limitation of algal productivity according to the model in 1988. The grey area indicates the depth range at which the maximum productivity, $P_{\max }$, is reached. This depth region of light saturation corresponds to the region of temperature limitation, because according to the Blackman model, temperature has an influence only on $P_{\max }$ and not on the slope $\alpha$ of the P-I curve. The depth region of temperature limitation is reduced at high $\mathrm{Chl} a$ concentrations (circles) because shading by algae reduces underwater light intensity and thus shifts the lightlimited regime upward.

$P_{\max }$ is larger than the effect of the seasonal change in solar radiation. The strong decline of the depth range of temperature limitation on $\mathrm{d} 110$ is caused by the light extinction due to the increased concentration of phytoplankton. Because light intensities are reduced, the maximum production rate is reached at shallower depth.

Increasing all water temperatures by $4^{\circ} \mathrm{C}$ moves the boundary of temperature-limited growth upward by about $1 \mathrm{~m}$. However, the increase in production caused by the raised water temperature has only a small effect on the total production and thus on the overall phytoplankton biomass. If water temperatures are increased by $4^{\circ} \mathrm{C}$ compared with the reference situation but turbulent diffusivities are kept unchanged, the onset of phytoplankton growth is shifted only very slightly to earlier times in the year (Fig. 5A,B, black dotted lines).

The above analysis shows that turbulent diffusion must be the dominant environmental parameter determining the timing of phytoplankton development. However, increasing turbulent diffusivities by even $50 \%$ does not cause a significant delay in phytoplankton growth (Fig. 5A,B, black solid line). Decreasing turbulent diffusivities to $1 / 2$ of the values employed in the reference simulation resulted in essentially the same Chl $a$ concentrations as increasing water temperatures by $4^{\circ} \mathrm{C}$ with a slight shift in the onset of phytoplankton growth to earlier times. However, this reduction in turbulent diffusivities cannot explain the interannual variation in the timing of phytoplankton growth. The interannual variations are rather the consequence of the differences in the interannual timing of the transition from rapid to slow mixing during spring. This transition is characterized by a change in the turbulent diffusivities over several orders of magnitudes (Fig. 5C), which is accompanied by the establishment of weak temperature stratification (see Fig. 3).

The prominent role of the transition from rapid to slow mixing for the onset of phytoplankton growth is demonstrated by a simulation in which the turbulent diffusivities from 1988 and 1990 were exchanged (i.e., the diffusivities from 1990 were employed to simulate phytoplankton in 1988 and vice versa; Fig. 5A,B, red line). All other environmental conditions (i.e., water temperature and solar radiation) and all model parameters were the same as in the reference simulation (Fig. 5A,B, blue line). This exchange in turbulence between years results in an almost perfect switch in phytoplankton dynamics. The latter also includes the short-term fluctuations in the Chl $a$ concentration (see, for example, d 85 in 1990, Fig. 5B), which apparently are caused by the temporal variations in the diffusivities (see d 85 in 1990; Fig. 5C, light blue lines). Note that the turbulent diffusivities in the original model are not arbitrary. They are not only responsible for the vertical transport of Chl $a$ but also for the transport of heat from the lake surface and thus determine the vertical temperature distribution. The agreement between simulated and observed temperature profiles indicates that the turbulent diffusivities employed in the original model are consistent with the conditions in the field.

The analysis above demonstrates that in deep Upper Lake Constance significant net growth of the phytoplankton population sets in when turbulence decreases to low levels, which is consistent with the critical turbulence concept proposed by Huisman et al. $(1999,2002)$. The derivation of the critical turbulence by Huisman et al. (1999) is based on several simplifying assumptions, including spatially and temporally constant diffusivities. In reality, turbulent diffusivities and light intensities often show substantial spatial and temporal variation even within the photic zone. However, there is a remarkable correspondence between the results from the critical turbulence concept and the results from our model that resolves the temporal and spatial variation in turbulent diffusion. For a background light extinction coefficient $\eta_{b}$ of $0.27 \mathrm{~m}^{-1}$ typical for Lake Constance, the critical turbulence predicted by Huisman et al. (1999) is on the order of $5 \times 10^{-4} \mathrm{~m}^{2} \mathrm{~s}^{-1}$. Crude as this prediction might be, it matches our results in Lake Constance, where the phytoplankton spring bloom develops when turbulent diffusion is reduced to values between $10^{-4} \mathrm{~m}^{2} \mathrm{~s}^{-1}$ and $10^{-3} \mathrm{~m}^{2} \mathrm{~s}^{-1}$ (Fig. 5). This supports the hypothesis that in deep lakes a strong reduction of turbulent diffusion is required for the phytoplankton spring bloom to develop.

In shallow lakes the timing of phytoplankton population growth in spring most likely is much less sensitive to the mixing conditions than in deep Upper Lake Constance. In shallow lakes the fraction of the solar radiation available to algae for photosynthesis depends primarily on water depth rather than on vertical mixing. Hence, the onset of phytoplankton growth in shallow lakes can be expected to depend more strongly on the seasonal pattern of solar 
radiation and on water temperature than in Upper Lake Constance.

Implications of the modeling results-The sensitivity study described above shows that the timing of the initial phytoplankton growth in deep monomictic lakes is determined by turbulent diffusion in the water column. Differences in the phytoplankton sinking velocity between $0.1 \mathrm{~m} \mathrm{~d}^{-1}$ and $1.0 \mathrm{~m} \mathrm{~d}^{-1}$ do not significantly affect phytoplankton development in winter and spring. This is plausible because vertical transport of phytoplankton due to sinking is small compared with transport by the large turbulent diffusion in the seasons investigated. The Peclet number, $P e=v_{\text {sed }} L / K_{z}$, provides a measure of the relative importance of transport by sedimentation and by turbulent diffusion, specifically $P e<<1$ implies that transport is dominated by turbulent diffusion. The sinking velocity of the phytoplankton is $v_{\text {sed }} \leq 1.0 \mathrm{~m} \mathrm{~d}^{-1}$, the turbulent diffusivity during the time period until the onset of phytoplankton growth is $K_{z} \geq 10^{-3} \mathrm{~m}^{2} \mathrm{~s}^{-1}$ and the typical length scale of the photic zone is $\mathrm{L} \leq 20 \mathrm{~m}$. With these values one obtains $P e \leq 0.23$, demonstrating that the transport of phytoplankton in winter and spring is predominantly determined by turbulent diffusion. Sinking of algae becomes important later in the season when the turbulent diffusivity in the thermocline can drop to values on the order $10^{-6} \mathrm{~m}^{2} \mathrm{~s}^{-1}$. Because the development of phytoplankton biomass in winter and spring is essentially independent of the phytoplankton sinking velocity, differences in sinking velocity between algal species most likely do not influence competition between algae species during this time of the year. A high net production (i.e., an efficient use of light or low respiration losses) seems to be an advantage in winter and spring, because mixing results in a low mean exposure to radiation of individual algal cells. The physiological requirements induced by the effect of mixing may hence cause the dominance of small algae in spring rather than the selection for species with small sedimentation rates (Sommer 1987).

Zooplankton have a negligible effect on the interannual variations of the onset of phytoplankton development in Upper Lake Constance. This is not surprising because from a food-web point of view plankton succession in spring is a bottom-up system, depending on primary production. From an ecosystem perspective, however, spring plankton succession is an externally forced food web driven by mixing. Even after the initial increase the temporal variation in phytoplankton biomass up to d 120 of each year is determined by mixing. Grazing increases the overall loss of phytoplankton and essentially reduces the long-term algae population growth. The short-term temporal variability in the Chl $a$ concentration, however, is the result of the physical forcing as indicated by the correlation between the temporal variations in simulated Chl $a$ and turbulent diffusivities (see Fig. 5). In some of the years with an early onset of the phytoplankton bloom (e.g., 1989; Fig. 4) grazing by zooplankton apparently is not sufficient to explain the decrease in the phytoplankton biomass after the initial increase. This suggests that in some years, additional factors such as phytoplankton community structure or nutrient availability (or both), influence the algal productivity and losses soon after the onset of phytoplankton growth.

Because turbulent diffusion is the key factor determining the onset of phytoplankton growth in deep Upper Lake Constance, the interannual changes in the timing of phytoplankton growth and the plankton succession depend on the interannual variations in the mixing dynamics. Mixing is the result of a complex interplay between heat fluxes at the lake surface affecting potential energy and wind forcing introducing kinetic energy into the water column. These driving mechanisms are determined by the meteorological conditions. Variability of meteorological forcing in spring must therefore be responsible for the interannual variations in the onset of phytoplankton growth in Upper Lake Constance and thus may be the origin of the changes in the interannual plankton succession in spring. Climate warming and the associated changes in the local meteorological conditions therefore are expected to alter the onset of phytoplankton growth and thus will have an effect on subsequent plankton succession.

\section{References}

Adrian, R., N. Walz, T. Hintze, S. Hoeg, and R. Rusche. 1999 Effects of ice duration on the plankton succession during spring in a shallow polymictic lake. Freshw. Biol. 41: 621-623.

Bannister, T. T. 1974. Production equations in terms of chlorophyll concentrations, quantum yield, and upper limit to production. Limnol. Oceanogr. 19: 1-12.

BÄUerle, E., AND U. GaedKe. 1998. Lake Constance-characterization of an ecosystem in transition. In E. Bäuerle, U. Gaedke and E. Stuttgart [eds.], Schweizerbartsche Verlagsbuchhandlung. Arch. Hydrobiol. Spec. Issues Adv. Limnol. 53: $1-610$.

, D. Ollinger, and J. Ilmberger. 1998. Some meteorological, hydrological, and hydrodynamical aspects of Upper Lake Constance. Arch. Hydrobiol. Spec. Issues Adv. Limnol. 53: $31-83$.

Blackman, F. F. 1905. Optima and limiting factors. Ann. Bot. 19: 281-295.

Bleiker, W., AND F. Schanz. 1997. Light climate as the key factor controlling the spring dynamics of phytoplankton in Lake Zürich. Aquat. Sci. 59: 135-157.

Carrias, J.-F., A. Thouvenot, C. Amblard, and T. SimeNGando. 2001. Dynamics and growth estimates of planktonic protists during early spring in Lake Pavin, France. Aquat. Microb. Ecol. 24: 163-174.

FlynN, K. J. 2003. Do we need complex mechanistic photoacclimation models for phytoplankton? Limnol. Oceanogr. 48: 2243-2249.

Gaedke, U., D. Ollinger, E. Bäuerle, and D. Straile. 1998. The impact of the interannual variability in hydrodynamic conditions on the plankton development in Lake Constance in spring and summer. Arch. Hydrobiol. Spec. Issues Adv. Limnol. 53: 565-585.

- AND D. Straile. 1994. Seasonal changes of the quantitative importance of protozoans in a large lake. An ecosystem approach using mass-balanced carbon flow diagrams. Mar. Microb. Food Webs 8: 163-188.

Geider, R. J., And B. A. Osborne. 1989. Respiration and microalgal growth: A review of the quantitative relationship between dark respiration and growth. New Phytol. 112: $327-341$ 
Geller, W. 1986. Diurnal vertical migration of zooplankton in a temperate great lake (L. Constance): A starvation avoidance mechanism? Arch. Hydrobiol. Suppl. 74: 160.

Goudsmit, G. H., H. Burchard, F. Peeters, and A. Wüest. 2002. Application of $\mathrm{k}-\varepsilon$ turbulence models to lakes - the role of internal seiches. J. Geophys. Res. 107: 3230-3242.

Gragnani, A., M. Scheffer, and S. Rinaldi. 1999. Top-down control of cyanobacteria: A theoretical analysis. Am. Nat. 153: 59-72.

Güde, H., H. Rossknecht, And G. Wagner. 1998. Anthropogenic impacts on the trophic state of Lake Constance during the 20th century. Arch. Hydrobiol. Spec. Issues Adv. Limnol. 53: 85-108.

Hamilton, D. P., and S. G. Schladow. 1997. Prediction of water quality in lakes and reservoirs. Part I-model description. Ecol. Model. 96: 91-110.

Häse, C. 1996. Die Vorhersage der Produktivität des Phytoplanktons im Bodensee unter Berücksichtigung der Temperatur sowie der spektralen Zusammensetzung des Unterwasser-Strahlungsfeldes. p. Ph.D. thesis. Univ. of Konstanz.

- U. Gaedke, A. Seifried, B. Beese, and M. M. Tilzer. 1998. Phytoplankton response to re-oligotrophication in large and deep Lake Constance: Photosynthetic rates and chlorophyll concentrations. Arch. Hydrobiol. Spec. Issues Adv. Limnol. 53: 159-178.

Huisman, J., K. Arrayas, U. Ebert, and B. Sommeijer. 2002. How do sinking phytoplankton species manage to persist? Am. Nat. 159: 245-254.

- AND OTHERS. 2004. Changes in turbulent mixing shift competition for light between phytoplankton species. Ecology 85: 2960-2970.

— P. van Oostveen, And F. J. Weissing. 1999. Critical depth and critical turbulence: Two different mechanisms for the development of phytoplankton blooms. Limnol. Oceanogr. 44: 1781-1788.

Huppert, A., B. Blasius, and L. Stone. 2002. A model of phytoplankton blooms. Am. Nat. 159: 156-171.

Jassby, A. D., And T. Platt. 1976. Mathematical formulation of the relationship between photosynthesis and light for phytoplankton. Limnol. Oceanogr. 21: 540-547.

Jürgens, K., S. A. Wickham, K. O. Rothhaupt, and B. Santer. 1996. Feeding rates of macrozooplankton and microzooplankton on heterotrophic nanoflagellates. Limnol. Oceanogr. 41: 1833-1839.

Leising, A. W., R. Horner, J. J. Pierson, J. Postel, and C. Halsband-Lenk. 2005. The balance between microzooplankton grazing and phytoplankton growth in a highly productive estuarine fjord. Prog. Oceanogr. 67: 366383.

Müller, H., B. Schöne, R. M. Pinto-Coelho, A. Schweizer, And T. Weisse. 1991. Seasonal succession of ciliates in Lake Constance. Microb. Ecol. 21: 119-138.

Omlin, M., R. Brun, And P. Reichert. 2001a. Biogeochemical model of Lake Zurich: sensitivity, identifiability and uncertainty analysis. Ecol. Model. 141: 105-123.

, P. Reichert, And R. Forster. 2001b. Biochemical model of Lake Zurich: Model equations and results. Ecol. Model. 141: 77-103.

Palmer, K. F., and D. Williams. 1974. Optical properties of water in the near infrared. J. Opt. Soc. Am. 64: 11071110 .

Pauli, H. R. 1989. A new method to estimate individual dry weights of rotifers. Hydrobiologia 186: 355-361.
Peeters, F., D. M. Livingstone, G.-H. Goudsmit, R. Kipfer, and R. Forster. 2002. Modeling 50 years of historical temperature profiles in a large central European lake. Limnol. Oceanogr. 47: 186-197.

Reynolds, C. S. 1997. Vegetation processes in the pelagic: A model for ecosystem theory. Ecology Institute.

Robertson, D. M., and R. A. Ragotzkie. 1990. Changes in the thermal structure of moderate to large sized lakes in response to changes in air temperature. Aquat. Sci. 52: 360-380.

SANTER, B., AND F. vAN DEN Bosch. 1994. Herbivorous nutrition of Cyclops vicinus: The effect of a pure algal diet on feeding, development, reproduction and life cycle. J. Plankt. Res. 16: 171-195.

Sommer, U. 1984. Sedimentation of principal phytoplankton species in Lake Constance. J. Plankt. Res. 6: 1-14.

- 1987. Factors controlling the seasonal variation in phytoplankton species composition - a case study for a deep, nutrient rich lake. Prog. Phycol. Res. 5: 123-179.

- Z. M. Gliwicz, W. Lampert, and A. Duncan. 1986. The PEG-model of seasonal succession of planktonic events in fresh waters. Arch. Hydrobiol. 106: 433-471.

Stefan, H. G., X. Fang, and M. Hondzo. 1998. Simulated climate change effects on year-round water temperatures in temperate zone lakes. Clim. Change 40: 547-576.

Straile, D. 2000. Meteorological forcing of plankton dynamics in a large and deep continental European lake. Oecologia 122: 44-50.

. 2005. Food webs in lakes-seasonal dynamics and the impact of climate variability, p. 41-50. In A. Belgrano, U. Scharler, J. Dunne and R. E. Ulanowicz [eds.], Aquatic food webs: An ecosystem approach. Oxford Univ. Press.

— AND W. Geller. 1998. Crustacean zooplankton in Lake Constance from 1920 to 1995: Response to eutrophication and reoligotrophication. Arch. Hydrobiol. Spec. Issues Adv. Limnol. 53: 255-274.

- K. Joehnk, And H. Rossknecht. 2003. Complex effects of winter warming on the physico-chemical characteristics of a deep lake. Limnol. Oceanogr. 48: 1432-1438.

Strom, S. L., M. A. Brainard, J. L. Holmes, and M. B. Olsen. 2001. Phytoplankton blooms are strongly impacted by microzooplankton grazing in coastal North Pacific waters. Mar. Biol. 138: 355-368.

Tian, R. C., D. Deibel, R. J. Thompson, and R. B. Rivkin. $2003 a$. Modeling of climate forcing on a cold-ocean system, Conception Bay, Newfoundland. Mar. Ecol. Prog. Ser. 262: $1-17$.

, A. F. Vezina, D. Deibel, and R. B. Rivkin. 2003 b. Sensitivity of biogenic carbon export to ocean climate in the Labrador Sea, a deep-water formation region. Glob. Biogeochem. Cycles 17: 1090. DOI: 10.1029/2002GB001969.

Tilzer, M. M. 1983. The importance of fractional lightabsorption by photosynthetic pigments for phytoplankton productivity in Lake Constance. Limnol. Oceanogr. 28: 833-846.

. 1988. Secchi disc-chlorophyll relationships in a lake with highly variable phytoplankton biomass. Hydrobiologia 162: 163-171.

Tirok, K., And U. GaedKe. 2006. Spring weather determines the relative importance of ciliates, rotifers and crustaceans for the initiation of the clear-water phase in a large, deep lake. J. Plankt. Res. 28: 361-373.

Townsend, D. W., M. D. Keller, M. E. Sieracki, and S. G. ACKLESON. 1992. Spring phytoplankton blooms in the absence of vertical water column stratification. Nature 360: 59-62. 
Weisse, T., N. Karstens, V. C. L. Meyer, L. Janke, S. Lettner, And K. Teichgräber. 2001. Niche separation in common prostome freshwater ciliates: The effects of food and temperature. Aquat. Microb. Ecol. 26: 167-179.

-, AND H. Müller. 1998. Planktonic protozoa and the microbial food web in Lake Constance. Arch. Hydrobiol. Spec. Issues Adv. Limnol. 53: 223-254.

, - R. M. Pinto-Coelho, A. Schweizer, D. SpringMANN, AND G. BALDRINGER. 1990. Response of the microbial loop to the phytoplankton spring bloom in a large prealpine lake. Limnol. Oceanogr. 35: 781-794.
Zenger, A., W. Anker, J. Ilmberger, and K. O. Münnich. 1990. Die Untersuchung der Windverhältnisse im westlichen Teil des Bodensees und die Umrechung von Landwinden auf Seebedingungen. Meteorol. Rundsch. 42: 42-51.

Received: 23 February 2006

Accepted: 29 September 2006

Amended: 25 September 2006 